\title{
Network connectivity is shown to change in C57BL/6 mice during a continuing immune response subsequent to tetanus toxoid hyperimmunization
}

\author{
Irena P Zivkovic ${ }^{1}$, Marijana M Stojanovic ${ }^{1}$, Vladimir Z Petrusic ${ }^{1}$, Aleksandra B Inic-Kanada ${ }^{1}$, \\ Mileva V Micic $^{2}$ \& Ljiljana A Dimitrijevic ${ }^{1}$ \\ 1 Institute of Virology, Vaccines and Sera - Torlak, Department of Research and Development, Vojvode Stepe 458, 11152 Belgrade, Serbia; \\ 2 Institute for Medical Research, Dr Subotica 4, PO Box 102, 11129 Belgrade, Serbia.
}

\begin{abstract}
We have already demonstrated (Stojanovic et al., 2009) a connection between tetanus toxoid (TTd) hyperimmunization and the induction of anti-phospholipid syndrome (APS) in BALB/c mice. Here we show that C57BL/6 mice subjected to an identical procedure do not exhibit any like pathology attributable to anti-phospholipid antibodies; we explain that this absence results from idiotypic connectivity. Six groups of C57BL/6 mice were hyperimmunized with TTd in aluminum hydroxide or glycerol, with or without pretreatments. Pretreated mice had been injected with polyclonal or nonspecific immune stimulators, such as complete Freund's adjuvant (CFA) or glycerol. The epitope specificity of induced antibodies was tested by indirect ELISA using a tetanus toxoid immunogen and these autoantigens: phospholipids, gangliosides, laminin. Idiotypic connectivity was tested by competitive ELISA and gauged from the degree to which the interaction of idiotypic/anti-idiotypic complementary antibodies was inhibited in the presence of immunized sera antibodies. Higher idiotypic connectivity was noted amongst pretreated mice. There was a positive correlation between higher connectivity and autoantibody levels that acted to favor the participation of natural autoantibodies in the inhibitory process. We conclude that idiotypic connectivity plays a protective role in immunization-induced autoimmunity.
\end{abstract}

Key terms: Autoantibodies, C57BL/6 mice, hyperimmunization, network

\section{INTRODUCTION}

Of the mechanisms that may contribute to autoantibody $(\mathrm{AAb})$ generation, those most often cited are molecular mimicry (Croxford et al., 2005, Samarkos \& Vaiopoulos, 2005) and polyclonal cell activation (Wickham \&Carr, 2004, Ramos et al., 2005). Antibodies (Abs) generated during immunization, whether immunogen- or self-specific, may have either public or private idiotypes (Ids) (Reilly \& Root, 1986, Hebert et al., 1990). These two Ids generate antiidiotype (anti-Id) Abs, respectively regarded as either autoantigens or AAbs; a network of interacting Ids and antiId Abs is thereby formed in consequence (Jerne, 1974, 2004 b, Vani et al., 2009). It is not suggested that the network potentially created by Id/anti-Id interactions following immunization is regulatory in nature; this is at variance with the network of Id/anti-Id interactions between natural autoantibodies (NAAbs) with public Id (Vani et al., 2008, Varela \& Coutinho, 1991, Coutinho, 1995). Since anti-Ids may be thought of as virtual AAbs, it is valid in this context to invoke the mechanisms of AAb induction when analyzing changes (be they qualitative or quantitative) in connectivity between Ids and anti-Ids induced during immunization, these mechanisms being selective polyclonal B cell expansion (Sutmuller et al., 1999) and/or an antigen-driven process (Shoenfeld, 1994, Atassi \& Casali, 2008) followed by mutations and strong Abs selection. Altered connectivity between Ids and anti-Ids may perhaps be the primum movens of autoimmune diseases; the loss of Id connectivity in the course of autoimmune diseases has been variously reported (Rossi et al., 1990, Very et al., 1993, Dwyer et al., 1986,
Pacheco-Garcia et al., 1999, Poletaev, 2002). The demonstratedly beneficial therapeutic effect of intravenous immunoglobulin (IVIG) administered to patients suffering from autoimmune disease, though its mode of operation is yet to be fully elucidated, lends credence to its importance in the restoration of Id connectivity (Dalakas, 2004, Kazatchkine \& Kaveri, 2001, Bayary et al., 2006).

In this paper we analyze changes in natural Id expression and $\mathrm{AAb}$ connectivity in the sera of $\mathrm{C} 57 \mathrm{BL} / 6$ mice hyperimmunized with tetanus toxoid (TTd) in conformity with six immunization protocols. TTd was the immunogen of choice because it is a partial structural homolog of beta2glycoprotein I ( $\beta 2$ GPI), a major autoantigen in antiphospholipid syndrome (APS)(Blank et al., 2002); furthermore, we have already demonstrated a link between TTd hyperimmunization and APS induction in BALB/c mice, when the severity of the pathology (fetal resorptions) was shown to be TTd administration context dependent (Stojanovic et al., 2009). The pathological response found in TTd-hyperimmunized BALB/c mice is in stark contrast to the case of $\mathrm{C} 57 \mathrm{BL} / 6$ mice where this type of reproductive pathology has not been observed. It is hypothesized that the absence (whatever the context of TTd administration) of this characteristic reproductive pathology subsequent to immunization in the C57BL/6 strain may be explained by a synchronized elevation of highly connected AAbs, which curb the effects of any pathological antibodies that may be present.

These were our hyperimmunization protocols: a hyperdose of TTd in either aluminum hydroxide or glycerol adjuvants was injected into non-, glycerol or CFA-pretreated C57BL/ 6 mice; we thus generated six groups of dissimilarly 
immunized animals from the six possible permutations of adjuvant and pretreatment.

Antibody profiles were studied over a period of 22 weeks with nine blood sera samples being taken at two-week intervals: preliminary samples of untreated sera were taken immediately before pretreatments, one week before the beginning of the course of immunizations; eight further samples of treated blood sera were taken every two weeks thereafter; a tenth and final sample was taken one week after the administration of the TTd booster dose. We were monitoring for changes in: Id/anti-Id connectivity; reactivity towards immunogen (TTd) and autoantigens ( $\beta 2 \mathrm{GPI}$, phospholipids, gangliosides and laminin); isotype composition.

The expression of natural Ids on TTd-immunized mouse Abs during the course of immunization was tracked via the inhibition of interaction in a complementary idiotypic pair: idiotype IgM DJ and its specific anti-idiotypic murine monoclonal antibody (MoAb) Y7.

The Y7 idiotope was first described occurring on human IgM molecules (IgM DJ) and then classified as natural. Natural, firstly, from its expression, detected on $5 \%$ to $8 \%$ of IgM from cord blood sera (Radulovic et al., 1997) and from the sera of patients suffering chronic lymphocytic leukemia (Ivanovic et al., 1990). Natural, secondly, from its IgM DJ properties, binding to ssDNA, lactic acid bacteria (LAB) and phosphorylcholine (PC) passively adsorbed to bovine serum albumin (BSA) (Dimitrijevic et al., 1999). The Y7 idiotope was assigned to the subgroup $\mathrm{V}_{\mathrm{H}} 3$ (Dimitrijevic et al., 2004 a).

The anti-idiotypic property of MoAb Y7 was characterized by its ability to inhibit IgM DJ immunogen binding to PC adsorbed to BSA (Dimitrijevic et al., 1992). This ability, indicative of internal image properties, leads to its typing as an analog of Ab2-beta. It may be regarded as an internal image of the natural idiotype. That the Y7 idiotype/MoAb Y7 pair has a regulatory function in a murine immune system was shown from its property of shaping the immune response against LAB in BALB/c mice (Dimitrijevic et al., 2004 b).

Our results show that the pretreatments shaped the profiles of analyzed AAbs, tending to the hypothesis that polyclonal-induced antibody Id interactions participated in both the pathology and in the control of the immune response. The absence in the $\mathrm{C} 57 \mathrm{BL} / 6$ strain of the characteristic reproductive pathology (fetal resorption) found earlier in BALB/c mice consequent to immunization (Stojanovic et al., 2009) may be explained by a synchronized elevation of these highly-connected AAbs neutralizing any threat posed by potentially pathological Abs.

\section{METHODS}

\section{Immunization and bleeding schedules}

10-week-old C57BL/6 female mice were used in the experiments. Pretreatments (a single dose of CFA or $2.5 \mathrm{M}$ glycerol (glyc) injected subcutaneously) were performed one week before the first administration of TTd. Non-pretreated, CFA-pretreated or glyc-pretreated mice were immunized with high doses of TTd (Institute of Virology, Vaccines and Sera - Torlak, Belgrade) mixed with either glyc (TTd/glyc) or $2 \%$ aluminum hydroxide ( $\mathrm{Al} ; \mathrm{TTd} / \mathrm{Al})$ as adjuvants. Doses of $200 \mu \mathrm{l}$ per mouse were administered subcutaneously three times at two-week intervals, $500 \mu \mathrm{g} / \mathrm{ml}$ TTd per $200 \mu \mathrm{l}$ dose. 16 weeks after the third dose, one additional booster dose of TTd was administered with an appropriate adjuvant. Thus we generated six groups of dissimilarly immunized animals (10 mice per group) from the six possible permutations of adjuvant and pretreatment.

The TTd used for immunization had passed the tests of specific and reverse toxicity to meet the requirements of the European Pharmacopoeia.

Samples of normal blood sera were collected simultaneously from all groups by bleeding from the retroorbital plexus prior to any intervention, i.e. immediately before pretreatments. Subsequent samples were similarly taken at two-week intervals for 16 weeks followed by one final sample taken one week after the administration of the TTd booster dose. Each group therefore underwent 10 separate bleedings inclusive of the initial taking of normal sera. The general methodology of our immunization and bleeding schedules has been previously described (Stojanovic et al., 2009; vide REFERENCES 36. infra).

The collected sera were complement depleted, aliquoted and stored at $-20{ }^{\circ} \mathrm{C}$ until used for analyses. The sample sera pools as assayed contained identical integrated volumes of sera, taken at identical time points (relative to the start of treatment) from identically immunized mice.

All animal experimentation was conducted in accordance with our country-specific Guiding Principles for the Care and Use of Laboratory Animals; these guidelines conform with the provisions of the Declaration of Helsinki (as revised and clarified); our experimentation received the approval of the Animal Institutional Care and Use Committee at the Institute of Immunology and Virology - Torlak.

\section{Indirect ELISA for the detection of specific sera IgG populations}

Detection of sera Abs specific for TTd, $\beta 2$ GPI, phospholipids or laminin was performed by indirect enzyme-linked immunosorbent assay (ELISA). Optimal sera dilutions were defined according to the results of preliminary experiments where randomly selected sera were analyzed at various dilutions. The sera Abs' reactivity towards specific antigens (Ags) was simultaneously analyzed in all discrete samples.

Ag-specific sera IgG binding was detected by biotinlabeled anti-mouse IgG (Sigma-Aldrich, St. Louis, Missouri, USA) or by using commercially available biotin-labeled Abs specific for murine IgG subclasses: anti-mouse IgG1, antimouse IgG2b, and anti-mouse IgG3 (ICN Biomedicals Inc., Aurora, Ohio, USA); anti-mouse IgG2c (Jackson ImmunoResearch Laboratories, West Grove, Pennsylvania, USA). The commercially available Abs were used in accordance with the manufacturers' instructions and incubated at room temperature $(1 \mathrm{~h})$. In all cases the ExtrAvidin ${ }^{\mathrm{TM}}$-peroxidase/o-phenylenediamine (OPD) system (Sigma-Aldrich Chemie GmbH, Steinheim, Germany) was used to visualize $\mathrm{Ag}-\mathrm{Ab}$ interactions. Absorbance was monitored at $492 \mathrm{~nm}$ and $620 \mathrm{~nm}\left(\mathrm{~A}_{492 / 620}\right)$. The cut-off value for each system was defined according to the $\mathrm{A}_{492 / 620}$ reading in negative control wells containing samples $1 \% \mathrm{w} / \mathrm{v}$ BSA in phosphate-buffered saline (PBS) $+3 \times$ SD. Sera samples were considered positive when the $\mathrm{A}_{492 / 620}$ value exceeded the cutoff value. 


\section{Detection of IgG specific for TTd and $\beta 2 G P I$}

The TTd used in ELISA had been produced at the Institute of Virology, Vaccines and Sera - Torlak, Belgrade. $\beta 2$ GPI was isolated from human plasma by a combination of precipitation techniques and ion-exchange chromatography (Stojanovic et al., 2009). Commercially available mouse anti-human $\beta 2 \mathrm{GPI}$ IgG1, clone 5F7, (ICN Biomedicals Inc., Aurora, Ohio, USA) was used for the identification of protein isolates.

Nunc MaxiSorp ${ }^{\mathrm{TM}}$ ELISA plates (Nunc, Roskilde, Denmark) were covered (50 $\mu \mathrm{l} /$ well) with TTd $(1 \mu \mathrm{g} / \mathrm{ml} \mathrm{TTd}$ in PBS) or $\beta 2 \mathrm{GPI}(10 \mu \mathrm{g} / \mathrm{ml} \beta 2 \mathrm{GPI}$ in PBS) by overnight adsorption $\left(4{ }^{\circ} \mathrm{C}\right) .1 \% \mathrm{w} / \mathrm{v}$ BSA in PBS was used for blocking at room temperature $(2 \mathrm{~h})$. Blocking and all subsequent steps in the ELISA were followed by washing with $0.05 \%(\mathrm{v} / \mathrm{v})$ Tween 20 in PBS (four times, $200 \mu \mathrm{l} /$ well). Appropriately diluted (1:800 in $1 \% \mathrm{w} / \mathrm{v}$ BSA in PBS) sera samples were incubated at room temperature (1h, $50 \mu \mathrm{l} /$ well).

Detection of $\operatorname{IgG}$ specific for mouse laminin

Mouse laminin (Sigma-Aldrich, St. Louis, Missouri, USA) (10 $\mu \mathrm{g} / \mathrm{ml}, 50 \mu \mathrm{l} /$ well) was adsorbed onto Nunc MaxiSorp ${ }^{\mathrm{TM}}$ microtiter plates $\left(4 \mathrm{~h}, 37^{\circ} \mathrm{C}\right)$. The plates were then washed (three times, $200 \mu \mathrm{l} /$ well PBS) and blocked with $1 \% \mathrm{w} / \mathrm{v}$ BSA in PBS. Diluted (1:400 in $1 \% \mathrm{w} / \mathrm{v}$ BSA in PBS, $0.05 \% \mathrm{v} /$ $\mathrm{v}$ Tween 20 in PBS) sera samples were added to the plates after washing four times $(200 \mu \mathrm{l} /$ well, $0.05 \% \mathrm{v} / \mathrm{v}$ Tween 20 in PBS) and then incubated overnight at $4{ }^{\circ} \mathrm{C}$.

Detection of IgG specific for phospholipids or gangliosides

For these ELISAs commercially available phospholipids and gangliosides (Sigma-Aldrich Chemie $\mathrm{GmbH}$, Steinheim) were used as antigens. The reactivities of sera IgG to the following phospholipids were analyzed: phosphatidylcholine (PtC), phosphatidylserine (PS), phosphatidylethanolamine (PE), phosphatidylinositol (PI), phosphatidylglycerol (PG) and cardiolipin (CL). Disialoganglioside $G_{D 1 b}$ and trisialoganglioside $\mathrm{G}_{\mathrm{T} 1 \mathrm{~b}}$ were used as antigens for the evaluation of specific anti-ganglioside sera IgG levels.

Phospholipids $(10 \mu \mathrm{g} / \mathrm{ml}$ in absolute ethanol, $50 \mu \mathrm{l} /$ well $)$ or gangliosides $(10 \mu \mathrm{g} / \mathrm{ml}$ in methanol, $50 \mu \mathrm{l} /$ well $)$ were immobilized onto Nunc PolySorp ${ }^{\mathrm{TM}}$ ELISA plates by evaporation at room temperature. After washing unbound Ags (three times, $200 \mu \mathrm{l} /$ well PBS) and blocking of free sites $\left(200 \mu \mathrm{l} 1 \% \mathrm{w} / \mathrm{v}\right.$ BSA in PBS; $\left.1 \mathrm{~h}, 37^{\circ} \mathrm{C}\right)$, the diluted $(1: 400$ in 1 $\% \mathrm{w} / \mathrm{v}$ BSA in PBS, $50 \mathrm{ml} /$ well) mice sera were added. To detect anti-phospholipid IgG the sera samples were incubated at room temperature $(1 \mathrm{~h})$; to detect anti-ganglioside IgG the sera samples were incubated overnight $\left(4{ }^{\circ} \mathrm{C}\right)$. All subsequent ELISA steps were followed by washing with $0.05 \% \mathrm{v} / \mathrm{v}$ Tween 20 in PBS (four times, $200 \mu \mathrm{l} /$ well).

Competitive ELISA for the detection of Y7 natural Id concentration changes in the sera of immunized mice

Two MoAbs were used to measure Y7 expression on sera Abs: biotin-labeled $\mathrm{F}(\mathrm{ab})_{2}$ of the anti-idiotypic murine MoAb $\mathrm{Y} 7\left(\mathrm{~F}(\mathrm{ab})_{2} \mathrm{Y7}\right.$-B) and $\mathrm{Y}^{+}$human MoAb IgM DJ. The Y7 concentration was estimated from the inhibition of $\mathrm{F}(\mathrm{ab})_{2} \mathrm{Y} 7$ $\mathrm{B}$ binding to $\operatorname{IgM}$ adsorbed onto plastic. IgM DJ was bound to a Nunc Maxisorp ${ }^{\mathrm{TM}}$ microtiter plate $(50 \mu \mathrm{l} /$ well) at a concentration of $500 \mathrm{ng} / \mathrm{ml} . \mathrm{F}(\mathrm{ab})_{2} \mathrm{Y} 7-\mathrm{B}(200 \mathrm{ng} / \mathrm{ml})$ was mixed with mouse sera diluted in $1 \% \mathrm{w} / \mathrm{v}$ BSA in PBS to a final dilution of $1: 100$, preincubated $\left(1 \mathrm{~h}, 25^{\circ} \mathrm{C}\right)$ in a water bath and further incubated with coated IgM DJ. ExtrAvidin ${ }^{\mathrm{TM}}$-peroxidase/OPD was used as a detector. Percentage inhibition (PI) was calculated after the determination of free $\mathrm{F}(\mathrm{ab})_{2}$ Y7-B using the standard curve of binding to IgM DJ.

\section{RESULTS}

TTd-specific (Ab1) and anti-ganglioside (Ab2) IgG antibodies

Time-dependent fluctuations in anti-TTd and antiganglioside sera IgG levels in TTd/Al and TTd/glycimmunized C57BL/6 mice are shown (Fig. 1 and Fig. 2). No matter which protocol was followed, it was found that TTd hyperimmunizations induced an intensive production of anti-TTd specific IgG. A challenge test with tetanus toxin confirmed that a protective immune response had developed in all groups (data not shown). In the context of Id networking, these TTd-specific Abs may be regarded as type Ab1. In all groups, a dramatic rise in sera anti-TTd IgG levels was observed during the main immunization phase, peaking at week six (two weeks after the administration of the third dose) and declining thereafter. Our results show that any difference in the binding characteristics and dynamics of these immunogen-specific sera IgG Abs was primarily a function of the adjuvant. The highest levels of immunogenspecific IgG were produced following TTd immunization in the presence of adjuvant $\mathrm{Al}$; levels were lower in an identically pretreated group immunized in the presence of adjuvant glyc. In the immediate post-immunization phase (prior to booster administration), anti-TTd IgG levels were found to decline with varying degrees of rapidity in mice immunized with TTd/glyc; in TTd/Al immunized mice, sera levels of TTd-specific IgG remained stable.

Following the booster TTd dose, however, a marked rise in the production of anti-TTd IgG was observed only in those immunizations administered in the presence of adjuvant glyc; anti-TTd IgG levels following immunizations given in the presence of adjuvant $\mathrm{Al}$ had already reached their plateaux and remained stable at those levels even after the final TTd booster dose.

In each group the increase in anti-TTd IgG sera levels was followed by an increase in anti-ganglioside IgG production. $G_{D 1 b}$ and $G_{T 1 b}$ are receptors for the tetanus toxin; from this it follows that the Ag binding site of antiganglioside IgG must be an internal image of the anti-TTd $\mathrm{Ab}$ reactive to the ganglioside binding site found on the tetanus Ag. In the context of idiotypic networks, antiganglioside Abs may be regarded as type Ab2. A comparison of time-dependent fluctuations in the levels of anti-TTd IgG and anti-ganglioside IgG confirmed that in all groups the appreciable rise in anti-TTd IgG production preceded the appreciable rise in anti-ganglioside IgG production. However, the most pronounced rises in anti-ganglioside $\mathrm{Ab}$ levels were seen during the post-immunization period (regardless of the immunization protocol followed), differing in this respect from the observed patterns of increase in TTdspecific IgG levels. 
A)

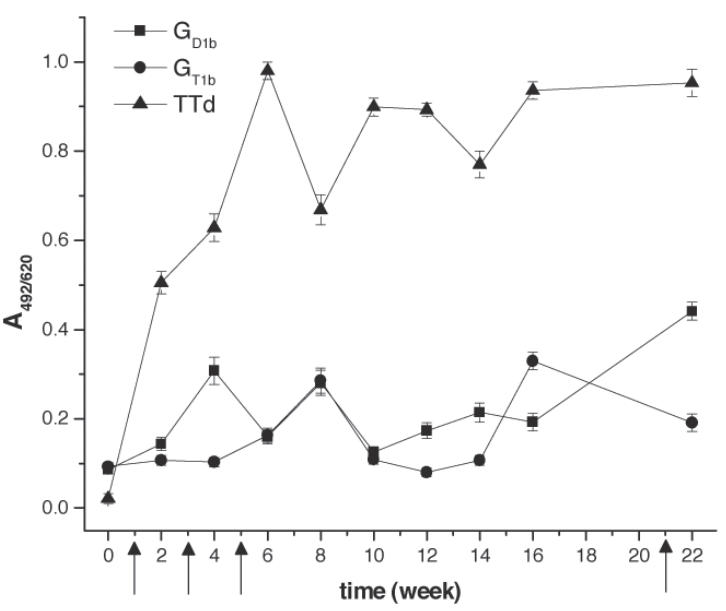

B)

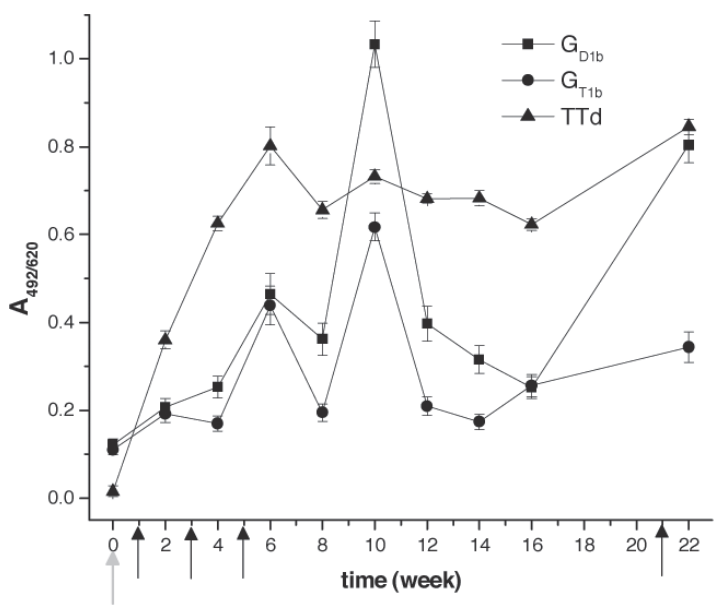

C)

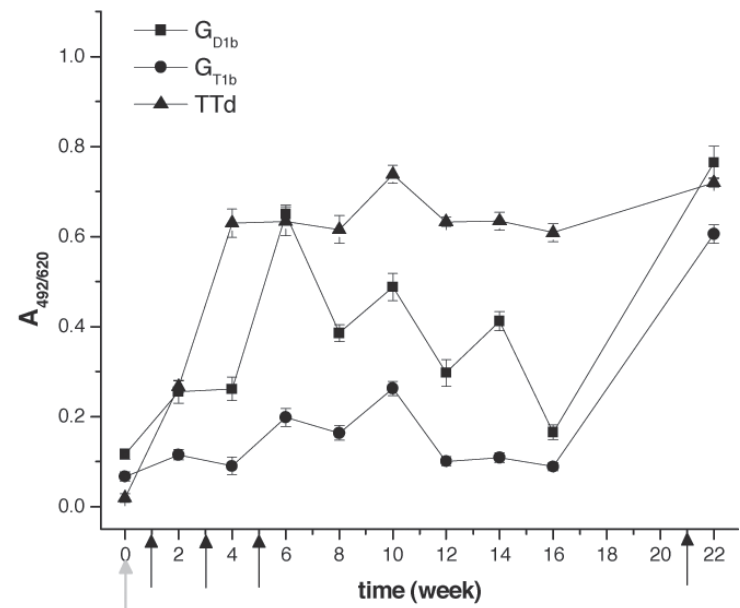

Figure 1: Time-dependant fluctuations in anti-TTd, anti- $G_{D 1 b}$ and anti- $\mathrm{G}_{\mathrm{T} 1 \mathrm{~b}}$ IgG levels within sera of non-pretreated (A), CFApretreated (B) or glyc-pretreated (C) C57BL/6 mice and hyperimmunized by TTd/Al. Light grey arrows indicate pretreatments and black arrows indicate TTd injections. Each sample (defined sera pool) was assayed in triplicate and calculated mean $\mathrm{A}_{492 / 620} \pm \mathrm{SE}$ are presented.
A)

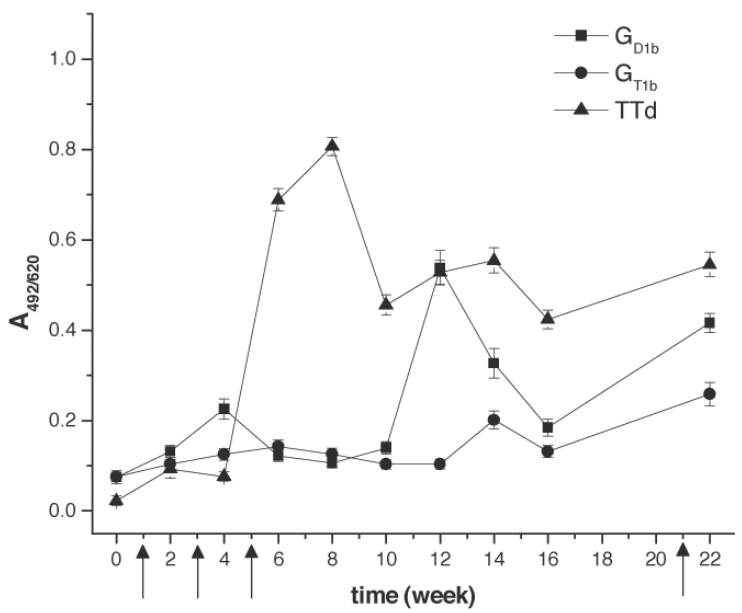

B)

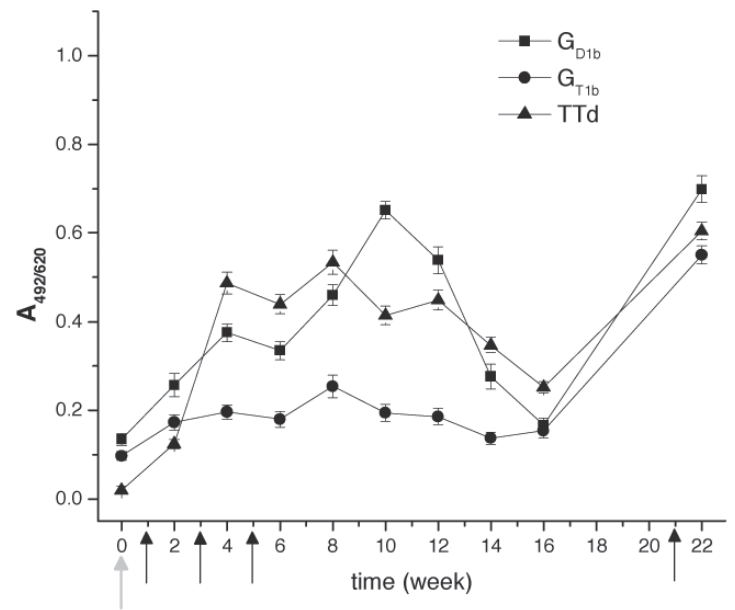

C)

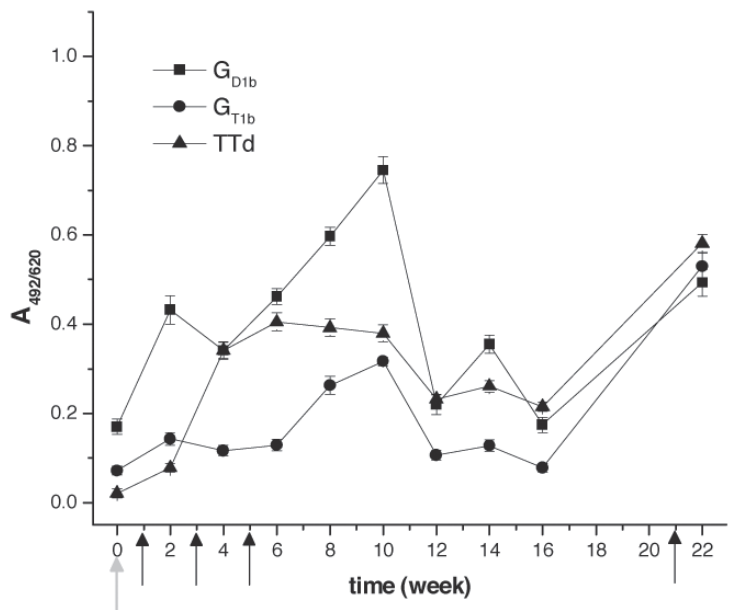

Figure 2: Time-dependant fluctuations in anti-TTd, anti- $G_{D 1 b}$ and anti- $G_{T 1 \mathrm{~b}}$ IgG levels within in sera of non-pretreated (A), CFApretreated (B) or glyc-pretreated (C) C57BL/6 mice and then hyperimmunized by TTd/glyc. Light grey arrows indicate pretreatments and black arrows indicate TTd injections. Each sample (defined sera pool) was assayed in triplicate and calculated mean $\mathrm{A}_{492 / 620} \pm \mathrm{SE}$ are presented. 
The levels of anti-ganglioside Abs were for the most part found to be higher among pretreated (be it with CFA or glyc) TTd-immunized C57BL/ 6 mice than among their nonpretreated TTd-immunized counterparts. Likewise, antiganglioside IgG production in response to the booster TTd dose was more intensive among pretreated mice.

Analyses of specific IgG subclass contributions to the entirety of the anti-ganglioside IgG pools showed that, for all experimental groups, a significant moiety of these contributing Abs belonged to subclasses IgG1 and IgG2c. The immunizations had no significant influence on either the dynamics or the contribution levels of any one specific antiganglioside IgG subclass; the analyses (Fig. 3) of the subclasses within anti- $\mathrm{G}_{\mathrm{D} 1 \mathrm{~b}}$ and anti- $\mathrm{G}_{\mathrm{T} 1 \mathrm{~b}}$ sera IgG pools (here shown as found in CFA-pretreated and TTd/glyc immunized mice only) are representative of all other mouse groups.

\section{Anti-phospholipid, anti- $\beta 2$ GPI and anti-laminin IgG antibodies}

The reactivity of TTd-hyperimmunized sera IgG to the autoantigens normally recognized by NAAbs (phospholipids, $\beta 2 \mathrm{GPI}$ ) was analyzed; sera reactivity to autoantigens bearing a partial structural similarity to the tetanus toxin/toxoid was analyzed by laminin or $\beta 2$ GPI.

Fluctuations in the levels of anti- $\beta 2$ GPI, antiphospholipids and anti-laminin IgG AAbs following specific immunizations were plotted against time (Fig. 4A and 4B; Fig. 5A and 5B; Fig. 6A and 6B).

Time-dependent changes in the reactivity of sera IgG to individual phospholipids were near identical, whatever the phospholipid type. In the context of NAAbs, anti-PtC is protective against infection and anti-PS IgG is active in the removal of apoptotic cells; because of these functions, they are the best explored of the phospholipids and so we have chosen PtC and PS to stand for phospholipids as a whole.

We have shown that TTd-hyperimmunization initiates production of significantly elevated levels of both anti- $32 \mathrm{GPI}$ IgG and phospholipid-specific IgG. Regardless of group,

A)

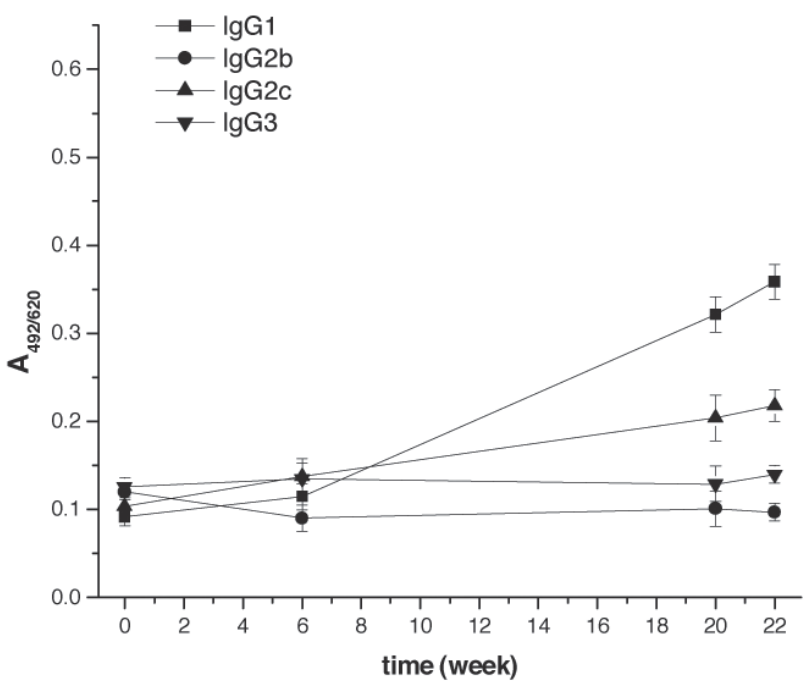

maximal sera levels of these AAbs were detected during the post-immunization period; however, the dynamics of production and the levels attained within individual groups were a function of the pretreatments administered. In pretreated mice, irrespective of adjuvant, anti- $\beta 2$ GPI and anti-phospholipid IgG reached maximal sera levels between the eight and tenth weeks following the course's commencement (Fig. 4A and 4B; Fig. 5A and 5B); in nonpretreated mice these concentrations rose gradually over a period of eight weeks during the post-immunization followup (Fig. 6A and 6B). The maximal attained sera concentrations of anti- $\beta 2$ GPI and anti-phospholipid IgG (evaluated from $\mathrm{A}_{492 / 620}$ ) were not adjuvant-dependent, ranking (highest to lowest): CFA-pretreated > glycpretreated $>$ non-pretreated. The shapes of curves depicting time-dependent fluctuations in the level of defined IgG AAbs (anti-ß2GPI and anti-phospholipid) were broadly similar for all the experimental groups (A and B on Fig. 4, Fig. 5 and Fig. 6).

No significant time-dependent fluctuations in antilaminin IgG pools were seen in any of the experimental groups (A and B on Fig. 4, Fig. 5 and Fig. 6).

The binding of $Y 7 F(a b)_{2}$ fragments to IgM DJ in the presence of TTdhyperimmunized mice sera

The probable influence of the previously described immunization procedures on Id/anti-Id interactions and on network perturbation was gauged from the extent to which the binding of anti-Id MoAb Y7 $\mathrm{F}(\mathrm{ab})_{2}$ to its corresponding Id $\left(\mathrm{Y}^{+} \mathrm{IgM} \mathrm{DJ}\right)$ was inhibited in the sera of the TTdimmunized C57BL/ 6 mice.

Levels of NAAbs vary, as one might expect given the broad physiological spectra across which they manifest (PI of normal sera pools was $32-50 \%$ ); over any extended period of time these levels can be expected to oscillate by as much as $20 \%$, thus only fluctuations exceeding this $20 \%$ bound were deemed significant. All immunization protocols induced

B)

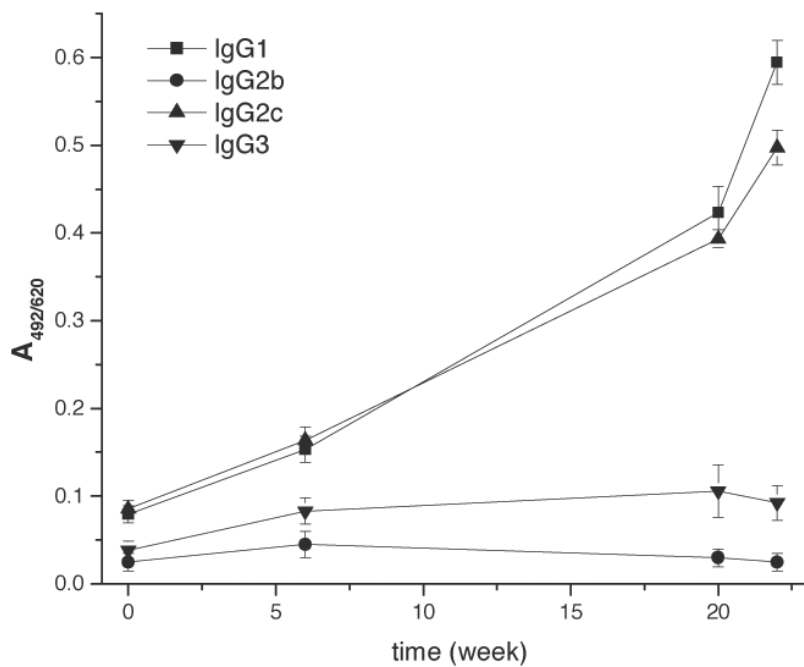

Figure 3: Influence of CFA-pretreatment and subsequent hyperimmunization by TTd/glyc on IgG subclasses levels within sera IgG pools specific for $G_{D 1 b}(A)$ and $G_{T 1 b}(B)$. Each sample (defined sera pool) was assayed in triplicate and calculated mean $A_{492 / 620} \pm S E$ are presented. 
A)

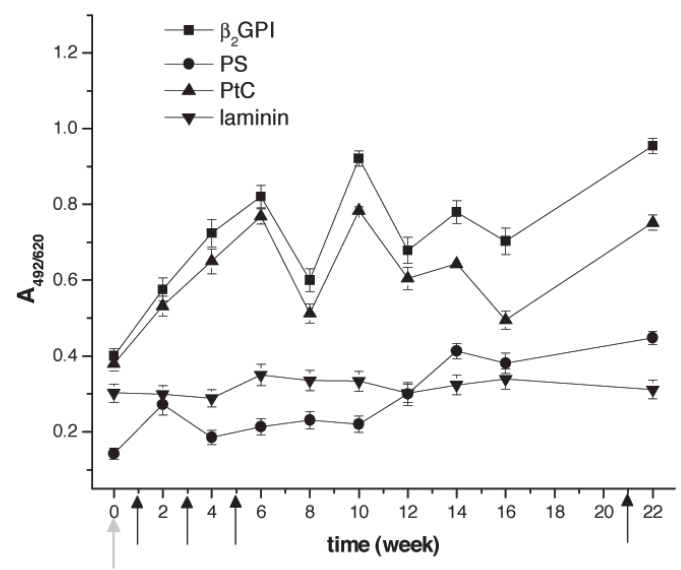

B)

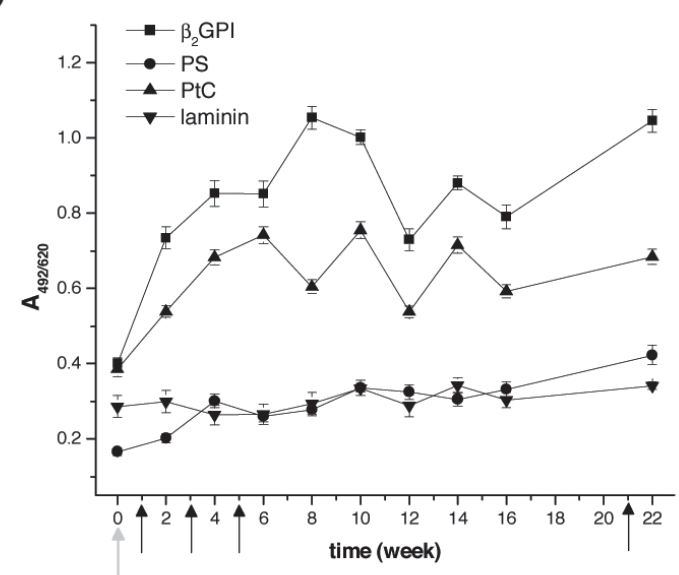

C)

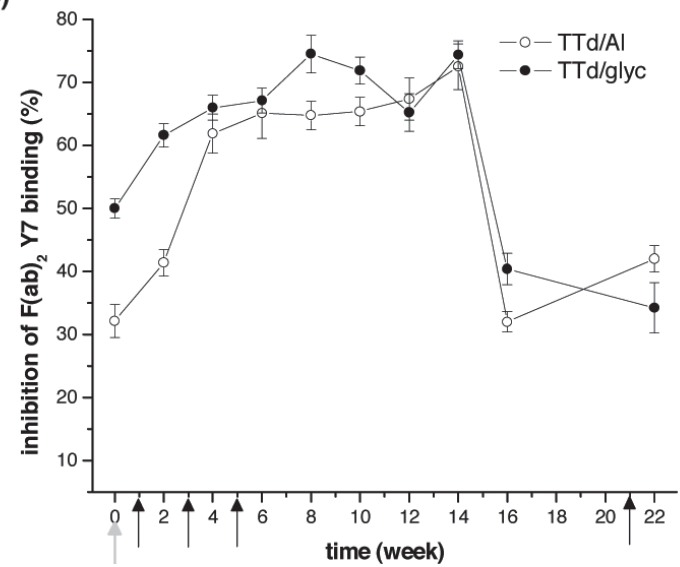

Figure 4: Time-dependent fluctuations in anti-B2GPI, antilaminin, anti-PS and anti-PtC IgG levels within sera of of glycpretreated $\mathrm{C} 57 \mathrm{BL} / 6$ mice and hyperimmunized by TTd/AI $(\mathrm{A})$ or by TTd/glyc (B). Each sample (defined sera pool) was assayed in triplicate and mean $A_{492 / 620} \pm \mathrm{SE}$ are shown. Chart $C$ plots inhibition of $\mathrm{F}(\mathrm{ab})_{2} \mathrm{Y} 7$ binding to IgM DJ $(\mathrm{Y} 7+\operatorname{IgM})$ as measured in sera pools collected at defined time-points from glycpretreated C57BL/6 mice immunized by TTd/Al or TTd/glyc. Each sample sera pool was assayed in triplicate and calculated mean $\mathrm{PI} \pm \mathrm{SE}$ are presented. Light grey arrows indicate pretreatment and black arrows indicate TTd injections.
A)

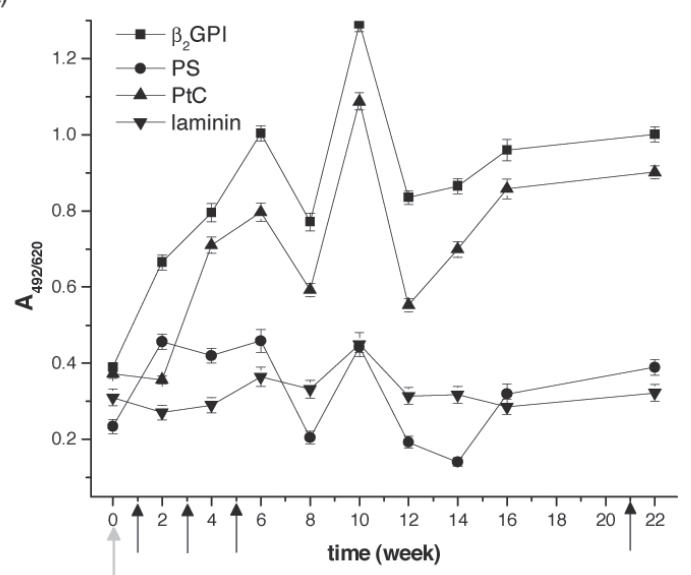

B)

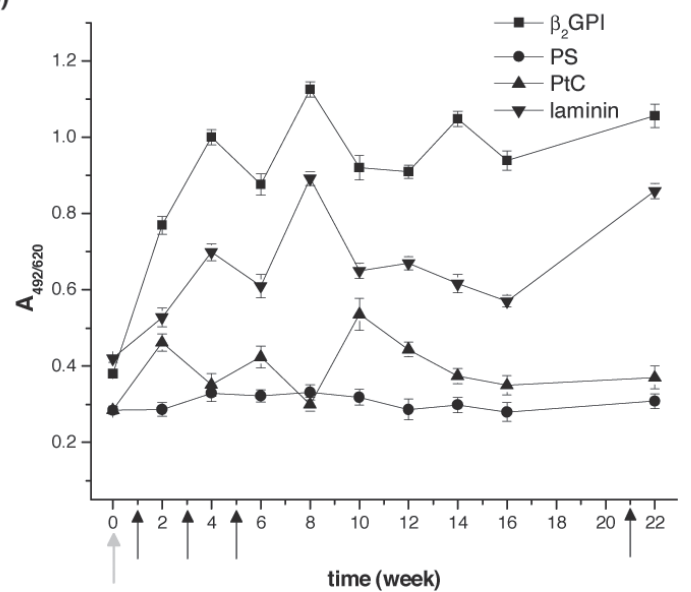

C)

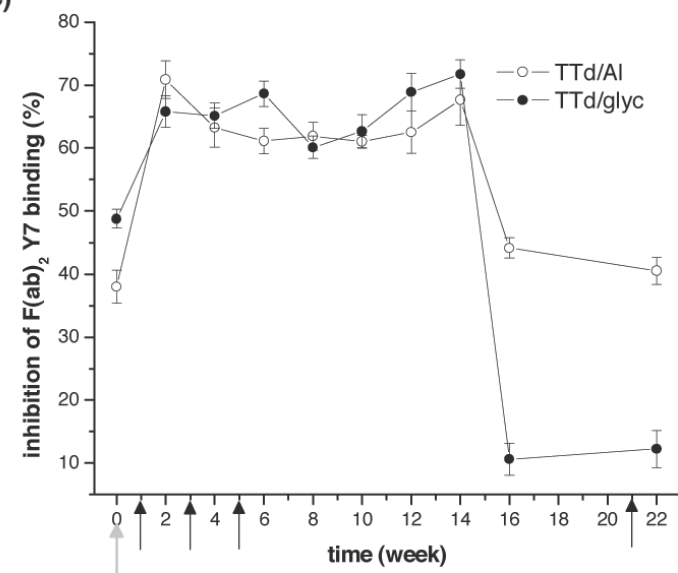

Figure 5: Time-dependent fluctuations in anti-B2GPI, antilaminin, anti PS and anti-PtC IgG levels within sera of of CFApretreated $\mathrm{C} 57 \mathrm{BL} / 6$ mice and hyperimmunized by TTd/AI (A) or by TTd/glyc (B). Each sample (defined sera pool) was assayed in triplicate and mean $A_{492 / 620} \pm \mathrm{SE}$ are shown. Chart $C$ plots inhibition of $F(a b)_{2} Y 7$ binding to IgM DJ $(Y 7+\operatorname{IgM})$ as measured in sera pools collected at defined time-points from CFA pretreated $\mathrm{C} 57 \mathrm{BL} / 6$ mice immunized by TTd/Al or TTd/glyc. Each sample sera pool was assayed in triplicate and calculated mean $\mathrm{PI} \pm \mathrm{SE}$ are presented. Light grey arrows indicate pretreatment and black arrows indicate TTd injections. 
A)

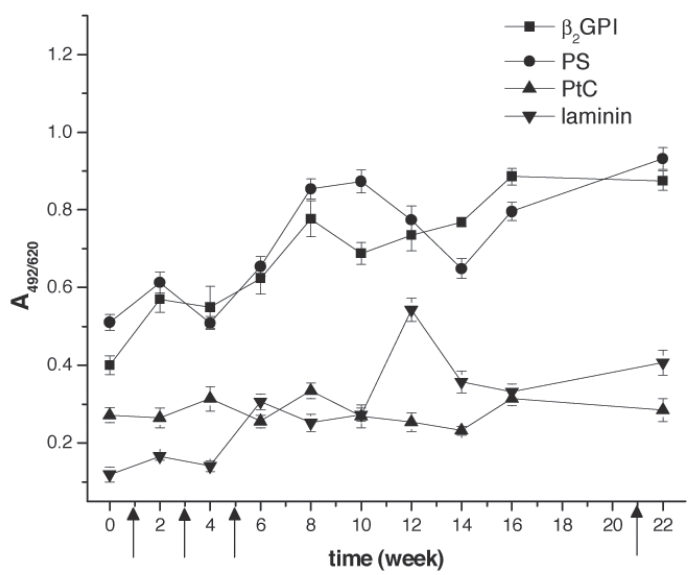

B)

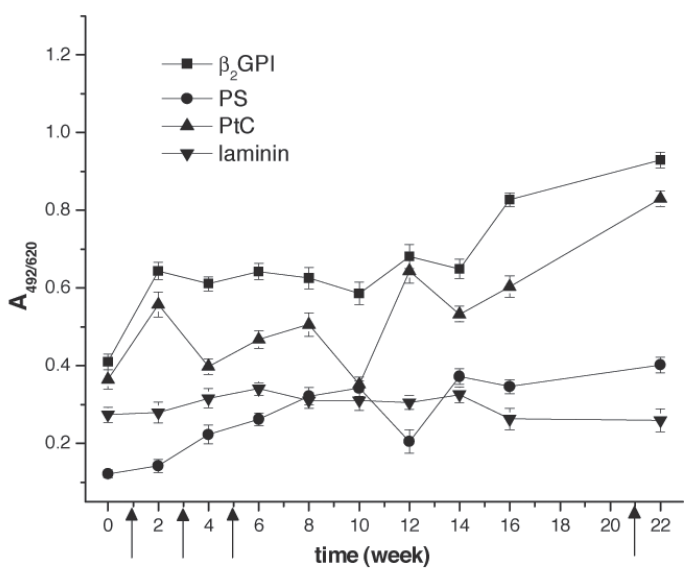

C)

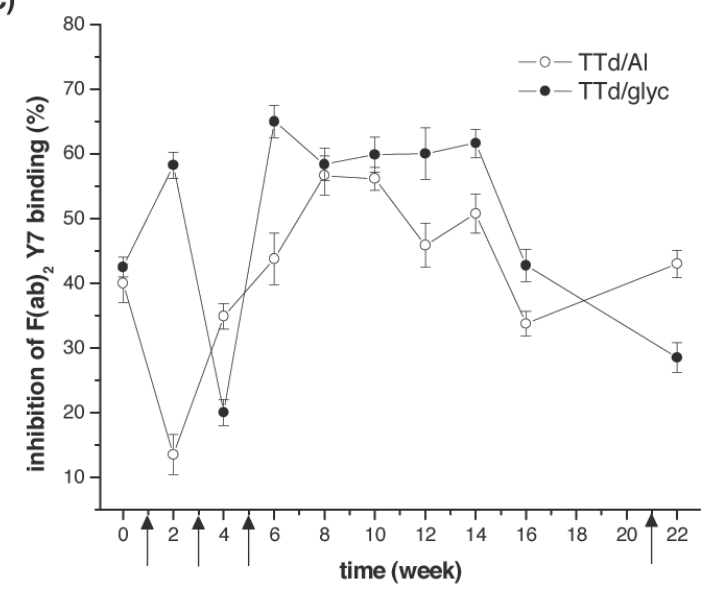

Figure 6: Time-dependent fluctuations in anti-B2GPI, antilaminin, anti-PS and anti-PtC IgG levels within sera of nonpretreated $\mathrm{C} 57 \mathrm{BL} / 6$ mice and hyperimmunized by TTd/Al (A) or by TTd/glyc (B). Each sample (defined sera pool) was assayed in triplicate and mean $A_{492 / 620} \pm \mathrm{SE}$ are shown. Chart $C$ plots inhibition of $F(a b) 2$ Y7 binding to $\operatorname{lgM} D J(Y 7+\operatorname{IgM})$ as measured in sera pools collected at defined time-points from non-pretreated C57BL/ 6 mice immunized by TTd/Al or TTd/glyc. Each sample sera pool was assayed in triplicate and calculated mean $\mathrm{PI} \pm \mathrm{SE}$ are presented. Black arrows indicate TTd injections. intensive fluctuations within NAAb pools conformant with the inhibition of MoAb Y7 F(ab) ${ }_{2}$ - IgM DJ binding (Fig. 4C, Fig. 5C and Fig. 6C). Whichever immunization protocol was followed, sera collected during the post-immunization period were more potent inhibitors of MoAb Y7 F $(\mathrm{ab})_{2}$ - IgM DJ interactions than were any of the normal C57BL/6 sera collected prior to intervention. The potential of sera Abs to inhibit MoAb Y7 F $(\mathrm{ab})_{2}$ - IgM DJ interactions was found to be time-dependent; a close analysis of the changes in this inhibitory potential revealed that network perturbations were more intensive and occurred more rapidly amongst pretreated mice than amongst non-pretreated mice. The adjuvant used not being a criterion, sera found to have the greatest inhibitory effect on MoAb Y7 F(ab) $)_{2}$ IgM DJ interactions (and the degree of effect did have to be significantly in excess of that produced by normal sera) were collected: in the case of CFA-pretreated mice after the first TTd dose; from glyc-pretreated mice after the second dose; from non-pretreated mice only at the very end of the immunization protocol.

For each group, the sera's marked inhibitory potential persisted until the ninth week post-immunization; its inhibitory potential then fell abruptly and was not significantly restored by the final TTd-booster dose administration.

\section{DISCUSSION}

In this paper we show that, in C57BL/6 mice, TTd hyperimmunization (whichever of our chosen protocols governed the immunizations) induces a high level of immunogen specific IgG production. There was a concomitant rise in the reactivity of sera IgG towards various autoantigens (AAgs), accompanied by quantitative disturbances in preexisting Id/anti-Id interactions demonstrated by the inhibition of MoAb Y7 and Y7+ IgM DJ binding.

Our results show that the TTd-specific and the autoreactive immune responses (which developed in tandem) are differently regulated: the immunogen-specific immune response was primarily shaped by the adjuvant used (whether $\mathrm{Al}$ or glyc); the dynamics and the intensities of the self-directed immune responses were linked to the pretreatments administered.

TTd-hyperimmunization in all groups induced a significant rise in reactivity towards the AAgs commonly recognized by NAAbs, as gangliosides, $\beta 2$ GPI and phospholipids. The reactivity of sera IgG towards mouse laminin (rarely recognized by mouse NAAbs) did not alter significantly within any experimental group, a result which, whilst implying that murine laminin tolerance is strictly regulated, is unsurprising given that anti-laminin IgGs are overtly pathogenic in the murine system. This invariance in reactivity accords with recent data showing that the robustness of any tolerance mechanism is AAg-specific and correlates inversely with the contributions of specific AAbs to the pool of NAAbs (Wang et al., 2003).

That autoimmunity is associated with the triggering of increases in $\mathrm{AAb}$ production and disturbances in Id networks is known; the trigger itself is not. Whether the initiating process is driven by antigens, by polyclonal B cell activation, or by both of these acting in concert, is as yet unelucidated but either or both are plausible candidates. 
Our pretreatments (CFA, glyc) and adjuvants (Al, glyc) are all potent polyclonal stimulators. Aluminum may be known, first and foremost, as a B cell stimulator but it also influences Ag-presenting cell activity (Brewer, 2006). Glycerol, as a chemical chaperone, is a polyclonal $\mathrm{T}$ cell activator (Ghumman et al., 1998). CFA (a mix of TLR agonists) acts on TLRs as expressed in C57BL/6 mice resulting in both $\mathrm{B}$ and $\mathrm{T}$ cell activation.

The detected secretion of both Th1 (INF- $\gamma$, TNF- $\alpha$, IL-12) and Th2 cytokines (IL-4 and IL-5) may be consequential to the influence of CFA upon T cells (Billiau \& Matthys 2001). CFA recruits natural memory cells (MZ B and B1) to assist in the interrogation of B cells (Bernasconi et al., 2002, Ha et al., 2006). This in turn leads to the generation of an Ag-specific adaptive immune response based on archetypes contained in and drawn from the pool of all anti-bacterial memories; thus there would appear to be latent or innate blueprints which can be used to produce an interim specific $\mathrm{Ab}$ response, a stopgap to afford the breathing-space necessary to permit a conventional adaptive response to develop. The importance of TLR activation in the production of AAbs is implicit in the fact that it was the CFA-pretreated mice that produced AAbs more quickly and in greater quantities than did any other experimental group.

Ags may also be drivers of anti- $\beta 2$ GPI and antiganglioside $\mathrm{Ab}$ production. TTd may incite anti- $\beta 2 \mathrm{GPI} A b$ production by molecular mimicry: TTd and $\beta 2 \mathrm{GPI}$ share partial similarities of three-dimensional structure (InicKanada et al., 2009). An alternative hypothesis is that antiganglioside Abs are generated in the context of Id/anti-Id networking; mice immunized (varying strategies) with gangliosides subsequently displayed poor antibody responses (Bowes et al., 2002). As the gangliosides $G_{D 1 b}$ and $\mathrm{G}_{\mathrm{T} 1 \mathrm{~b}}$ are tetanus toxin receptors, an antigen-binding site found on an anti-ganglioside IgG might be an internal image of an anti-TTd Ab, reactive towards the ganglioside-binding site found on the tetanus antigen. In an idiotypic network, anti-TTd IgG might be typed as Ab1 with anti-ganglioside Abs typed as Ab2. This hypothesis is not in conflict with the sequence of events observed during specific Ab secretion: an appreciable rise in anti-TTd IgG sera concentration precedes the secretion of anti-ganglioside IgG. The increase in IgG2c ganglioside-specific antibodies after the TTd booster dose carries with it the implication that both Id/anti-Id interactions and Th1 cytokines are together involved in the synthesis of these former.

If maintenance of tolerance to self-structures is paramount in the immune system hierarchy then protection against those microbial invaders which impersonate (to a greater or lesser extent) host self-structures is problematic; how to mount a defense against the invader without compromising this tolerance and inducing an autoimmune pathology? It seems inevitable that, in any rapid defense mounted, a tipping-point will be reached when polyclonal activation normally preventive (in a heuristically homeostatic system) of autoimmunity will itself initiate a runaway autoimmune response.

If polyclonal B cell activation alone (or changes in quantitative interactions in the public Id) acts as the trigger for autoimmunity then the regulatory potential of the NAAb network is nullified; the constitutive recurrence (dynamic and metadynamic properties of interactions) of the public Id would be neglected and thus the full regulatory potential of NAAbs could never be exploited. Thus polyclonal B cell activation cannot be the sole culprit; somatic mutation and affinity maturation are prerequisites aided implicitly by regulator-T cells, helper-T and follicular B cells; a variety of antigens and strong autoantibodies are complicit.

It follows then that any ability to neutralize the threats posed by the multiplicity of near self-similar invasive bodies must be integral to a system in its entirety (reliant upon mutations in the public Id which whilst connected retains it utility) thus explaining the observed differences in the responses of $\mathrm{BALB} / \mathrm{C}$ and $\mathrm{C} 57 \mathrm{BL} / 6$ mice to $\mathrm{TTd}$ hyperimmunization.

Any heightened NAAb connectivity recruits autoreactive $B$ cells to the network; these themselves then become subject to the dynamics of the network, both limiting their clonal reproductivity and inhibiting $A b$ secretion. These dynamics also shepherd NAAb complements into the network fold. The sequence then becomes recursively self-iterating, gathering in all functionally autoreactive B cells subsequently produced.

It is worth noting that, within newly produced or immunization-produced AAb pools, perturbances and synchronous fluctuations in AAb levels were induced; we were either witnessing a cross-reactivity with NAAbs or the AAbs were themselves members of a NAAb network. We saw that a quantitative disturbance in preexisting Id/anti-Id interactions was induced by TTd hyperimmunization and that this was most noticeable in groups pretreated with CFA or glyc.

As stated, if polyclonal B cell activation is the primary factor in the initiation and continued induction of autoimmunity in BALB/c mice, then the ability of C57BL/ 6 mice to sidestep the threats arising from TTd hyperimmunization must be genetically integral to their immune system. Let us now attempt to explore this issue further.

The question: why does an identical immunization protocol induce a characteristic pathology (APS with fetal resorption) in BALB/c mice yet not do so in C57BL/6 mice? Consider first the numerous $\mathrm{V}_{\mathrm{H}}$ functional genes, differently expressed in different mouse strains. The relative map positions of the $\mathrm{V}_{\mathrm{H}}$ gene families in Igha and Ighb haplotypes are indistinguishable (Brodeur et al., 1988) and it is thus unlikely that the differential expression of $\mathrm{V}_{\mathrm{H}}$ families in $\mathrm{BALB} / \mathrm{C}$ and C57BL/6 mice is due to differences in $\mathrm{V}_{\mathrm{H}}$ gene organization. But it is documented that, in the C57BL/ 6 strain, anti-PtC Abs are mainly encoded by $\mathrm{V}_{\mathrm{H}} 1$ immunoglobulin heavy-chain variable region gene families; usage of the $\mathrm{V}_{\mathrm{H}} 2$ gene predominates in BALB/c mice. In the anti-PtC $\mathrm{Ab}$, heavy-chains encoded by the $\mathrm{V}_{\mathrm{H}} 1$ and $\mathrm{V}_{\mathrm{H}} 2$

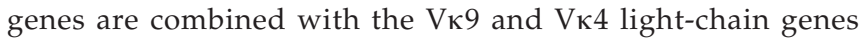
respectively; $\mathrm{J}_{\mathrm{H}} 1$ genes combine with third complementary determining regions (CDR3s) of longitudinal homogeneity (Poncet et al., 1990, Carmack et al., 1990). Diversity within the anti-PtC $\mathrm{Ab}$ pools encoded by $\mathrm{V}_{\mathrm{H}} 1$ is assured by the high number of genes within that family, greatly increasing the likelihood that a broad spectrum of germ-line encoded end products will be generated (Seidl et al., 1999).

AAbs encoded by the significantly smaller $\mathrm{V}_{\mathrm{H}} 2$ family $\left(\mathrm{V}_{\mathrm{H}} \mathrm{Q} 52\right.$ gene family) display a greater diversity ( $\mathrm{N}$-region additions and variable length CDR3s) and so may easily slip 
through the regulatory net of natural Id/anti-Id interactions (Seidl et al., 1999). That synchronous fluctuations within newly produced or immunization-produced $\mathrm{AAb}$ pools were seen in C57BL/6 mice (with Id/anti-Id disturbance most noticeable in pretreated animals) suggests that it is intense polyclonal stimulation in a milieu of Id/anti-Id interactions that keeps the system in an organized state, with any detectable pathologies eliminated either through hysteresis or the total suppression of an autoimmune response.

Self-tolerance is the sine qua non of the immune system as we understand it. Each new immune response is deemed to be generated from and within a network of preexisting $\mathrm{NAAb}$ idiotypes. It follows that a tetanus toxoid-specific immune response will be generated within the interstices of Id/anti-Id interactions framing phospholipid-specific NAAbs. Abs to Ags such as PtC must exist innately, a priori to any $\mathrm{Ag}$ first encounter; it is hard if not impossible to posit that somatic mutation and selection alone can create and account for specificities to Ags yet to be encountered. It follows that an imperfect or inchoate NAAb network, consequential to a genetically predetermined deficiency in the library of NAAb producing cells, may leave BALB/c mice vulnerable to APS (Avrameas et al., 2007). The more diverse palette of AAbs found in C57BL/6 mice has painted a network capable of preventing APS.

\section{ACKNOWLEDGEMENTS}

This research was supported by a grant from the Ministry of Science and Technological Development of Republic of Serbia (contract numbers 142020 and 172049).

\section{REFERENCES}

1. ATASSI MZ, CASALI P (2008) Molecular mechanisms of autoimmunity. Autoimmunity 41: 123-32

2. AVRAMEAS S, TERNYNCK T, TSONIS IA, LYMBERI P (2007) Naturally occurring B-cell autoreactivity: a critical overview. J Autoimmun 29: 213-8

3. BAYARY J, DASGUPTA S, MISRA N, EPHREM A, VAN HUYEN JP, DELIGNAT S, HASSAN G, CALIGIURI G, NICOLETTI A, LACROIXDESMAZES S, KAZATCHKINE MD, KAVERI S (2006) Intravenous immunoglobulin in autoimmune disorders: an insight into the immunoregulatory mechanisms. Int Immunopharmacol 6: 528-34

4. BERNASCONI NL, TRAGGIAI E, LANZAVECCHIA A (2002) Maintenance of serological memory by polyclonal activation of human memory B cells. Science 298: 2199-202

5. BILLIAU A, MATTHYS P (2001) Modes of action of Freud's adjuvants in experimental models of autoimmune diseases. J Leuk Biol 70:84960

6. BLANK M, KRAUSE I, FRIDKIN M, KELLER N, KOPOLOVIC J, GOLDBERG I, TOBAR A, SHOENFELD Y (2002) Bacterial induction of autoantibodies to beta2-glycoprotein-I accounts for the infectious etiology of antiphospholipid syndrome. J Clin Invest 109:797-804

7. BOWES T, WAGNER ER, BOFFEY J, NICHOLL D, COCHRANE L, BENBOUBETRA M, CONNER J, FURUKAWA K, FURUKAWA K, WILLISON HJ. (2002) Tolerance to self gangliosides is the major factor restricting the antibody response to lipopolysaccharide core oligosaccharides in Campylobacter jejuni strains associated with Guillain-Barré syndrome. Infect Immun. 70:5008-18

8. BREWER JM (2006) (How) do aluminum adjuvants work? Immunol Lett 102: 10-5

9. BRODEUR PH, OSMAN GE, MACKLE JJ, LALOR TM (1988) The organization of the mouse Igh-V locus. Dispersion, interspersion, and the evolution of VH gene family clusters. J Exp Med 168: 2261-78

10. CARMACK CE, SHINTON SA, HAYAKAWA K, HARDY RR (1990) Rearrangement and selection of VH11 in the Ly-1 B cell lineage. J Exp Med 172: 371-4
11. COUTINHO A (1995) The network theory - 21 years later. Scand. J. Immunol 42: 3-8

12. CROXFORD JL, ANGER HA, MILLER SD (2005) Viral delivery of an epitope from Haemophilus influenzae induces central nervous system autoimmune disease by molecular mimicry. J Immunol 174: 907-17

13. DALAKAS MC (2004) Intravenous immunoglobulin in autoimmune neuromuscular diseases. JAMA 291: 2367-75

14. DIMITRIJEVIC LJ, RADULOVIC M, CIRIC B, ODRLJIN T, JANKOV R, AND MARZARI R (1992) Immunochemical characterization of a murine monoclonal anti-idiotypic antibody. J. Immunoassay 13: 181196

15. DIMITRIJEVIĆ LA, RADULOVIĆ MI, CIRIĆ BP, PETRIĆEVIĆ MM, INIĆ AB, NIKOLIĆ DN, APOSTOLSKI S (1999) Human monoclonal IgM DJ binds to ssDNA and human commensal bacteria. Hum Antibodies 9: 37-45

16. DIMITRIJEVIC LA, STOJANOVIC M, CIRIC B, RADULOVIC M, STOJANOVIC R, POPOVIC Z, INIC-KANADA A, ZIVKOVIC I (2004 a) Expression of $Y 7$ cross-reactive idiotope on human IgM molecules. Immunol Invest 33: 1-14

17. DIMITRIJEVIC L, ZIVANCEVIC-SIMONOVIC S, STOJANOVIC M, INIC-KANADA A, ZIVKOVIC I (2004 b) The possible role of natural idiotopes in immune memory. Clin Dev Immunol 11: 281-5

18. DWYER DS, VAKIL M, KEARNEY JF (1986) Idiotypic network connectivity and a possible cause of myasthenia gravis. J Exp Med 164: 1310-8

19. GHUMMAN B, BERTRAM EM,WATTS TH (1998) Chemical chaperones enhance superantigen and conventional antigen presentation by HLA-DM-deficient as well as HLA-DM-sufficient antigen-presenting cells and enhance IgG2a production in vivo. J Immunol 161: 3262-70.

20. HA SA, TSUJI M, SUZUKI K, MEEK B, YASUDA N, KAISHO T, FAGARASAN S (2006) Regulation of B1 cell migration by signals through Toll-like receptors. J Exp Med 203: 2541-50

21. HÉBERT J, BERNIER D, BOUTIN Y, JOBIN M, MOURAD W (1990) Generation of anti-idiotypic and anti-anti-idiotypic monoclonal antibodies in the same fusion. Support of Jerne's Network Theory. J Immunol 144: 4256-61

22. INIC-KANADA A, STOJANOVIC M, ZIVKOVIC I, KOSEC D, MICIC $\mathrm{M}$, PETRUSIC V, ZIVANCEVIC-SIMONOVIC S, DIMITRIJEVIC L (2009) Murine monoclonal antibody 26 raised against tetanus toxoid cross-reacts with beta2-glycoprotein I: its characteristics and role in molecular mimicry. Am J Reprod Immunol 61:39-51

23. IVANOVIĆ V, POPOVIĆ L, KOVACINA K, DIMITRIJEVIĆ L, ILIĆ D, PIROZKOV A, BALTIĆ V. (1990) Detection of cross-reacting idiotypes in sera of lymphoma patients by inverse monoclonal radioimmunoassay. Acta Haematol 84: 64-7

24. JERNE NK (1974) Towards a network theory of the immune system. Ann Immunol (Paris) 125C: 373-82

25. KAZATCHKINE MD, KAVERI S (2001) Immunomodulation of autoimmune and inflammatory diseases with intravenous immune globulin. N Engl J Med 345: 747-55

26. PACHECO-GARCÍA U, TOVAR-RIVERA T, PADIERNA-OLIVOS L, ROJAS-ESPINOSA O, SÁNCHEZ-COLÓN S, GUTIÉRREZARMENTA M, RIVERA-BENÍTEZ C, MASSO-ROJAS F, SÁNCHEZGARCÍA FJ (1999) Altered pattern of connectivity in serum immunoglobulins from pemphigus vulgaris patients. Scand J Immunol 49: 424-30

27. POLETAEV AB (2002) The immunological homunculus (immunculus) in normal state and pathology. Biochemistry (Moscow) 67: 721-731

28. PONCET P, HUETZ F, MARCOS MA, ANDRADE L (1990) All VH11 genes expressed in peritoneal lymphocytes encode anti-bromelaintreated mouse red blood cell autoantibodies but other VH gene families contribute to this specificity. Eur J Immunol 20: 1583-9

29. RADULOVIC M, CIRIC B, JURISIC A, JANKOV R, APOSTOLSKI S, ZIVANCEVIC-SIMONOVIC S, DIMITRIJEVIC LJ. Expression of Y7 idiotope on IgM molecules from cord sera. In: Lukic M, MostaricaStojkovic M, Cuperlovic K, Colic M, eds. Immune regulation in health and disease. London: Academic Press; 1997. p. 205-11

30. RAMOS OP, SILVA EE, FALCAO DP, MEDEIROS BM (2005) Production of autoantibodies associated with polyclonal activation in Yersinia enterocolitica O: 8-infected mice. Microbiol Immunol 49(2):129-37

31. REILLY TM, ROOT RT (1986) Production of idiotypic and antiidiotypic antibodies by BALB/c mice in response to immunizations with glucagon, vasopressin, or insulin: supporting evidence for the network concept. J Immunol 137: 597-602 
32. ROSSI $\mathrm{F}$, GUILBERT B, TONNELLE $\mathrm{C}$, TERNYNCK T, FUMOUX $\mathrm{F}$, AVRAMEAS S, KAZATCHKINE MD (1990) Idiotypic interactions between normal human polyspecific IgG and natural IgM antibodies. Eur J Immunol 20: 2089

33. SAMARKOS M., VAIOPOULOS G (2005) The role of infections in the pathogenesis of autoimmune diseases. Curr Drug Targets Inflamm Allergy 4: 99-103

34. SEIDL KJ, WILSHIRE JA, MACKENZIE JD, KANTOR AB, HERZENBERG LA, HERZENBERG LA (1999) Predominant VH genes expressed in innate antibodies are associated with distinctive antigen-binding sites. Proc Natl Acad Sci USA 96: 2262-7

35. SHOENFELD Y (1994) Idiotypic induction of autoimmunity: a new aspect of the idiotypic network. FASEB J 8: 1296-301

36. STOJANOVIC M, ZIVKOVIC I, INIC-KANADA A, PETRUSIC V, MICIC M, DIMITRIJEVIC L (2009) The context of tetanus toxoid administration influences the outcome of antigen-specific and selfdirected humoral immune response. Microbiol Immunol 53: 89-100

37. SUTMULLER M, BAELDE JJ, MADAIO MP, BRUIJN JA, DE HEER E (1999) Idiotype usage by polyclonally activated B cells in experimental autoimmunity and infection. Clin Exp Immunol 115: $275-80$
38. VANI J, CHATTERJEE I, SHAILA MS, NAYAK R, CHANDRA NR (2009) Structural basis for the function of anti-idiotypic antibody in immune memory. Mol Immunol 46: 1250-5

39. VANI J, ELLURU S, NEGI VS, LACROIX-DESMAZES S, KAZATCHKINE MD, BAYARY J, KAVERI SV (2008) Role of natural antibodies in immune homeostasis: IVIg perspective. Autoimmun Rev 7: 440-4

40. VARELA JF, COUTINHO A (1991) Second generation immune networks. Immunology Today 12: 159-66

41. VERY DL JR, PANKA DJ, WEISSMAN D, WYSOCKI L, MANSER T, Marshak-Rothstein A (1993) Lack of connectivity between the induced and autoimmune repertoires of $1 \mathrm{pr} / \mathrm{lpr}$ mice. Immunology 80: $518-26$

42. WANG C, KHALIL M, RAVETCH J, DIAMOND B (2003) The naive B cell repertoire predisposes to antigen-induced systemic lupus erythematosus.J Immunol 170:4826-32

43. WICKHAM S, CARR DJ (2004) Molecular mimicry versus bystander activation: herpetic stromal keratitis. Autoimmunity 37: 393-7 